\title{
Vibratory bed assisted infrared drying of parboiled rice and its rice bran stability
}

\author{
Pattarachai Vichaiya, Jiraporn Sripinyowanich Jongyingcharoen* \\ Department of Agricultural Engineering, Faculty of Engineering, King Mongkut's Institute of Technology Ladkrabang, Bangkok, \\ Thailand
}

\begin{abstract}
The purposes of this research were divided into two parts: (1) to determine the drying characteristics and quality of parboiled paddy undergoing vibratory bed assisted infrared (VIR) drying, and (2) to study the stability of rice bran from the VIR-dried parboiled paddy. Infrared (IR) drying and hot air (HA) drying were applied for comparison purpose. For the experiment 1, VIR drying of parboiled paddy provided the best drying characteristics with the shortest drying time of $50 \mathrm{~min}$ and the maximum drying rate of $0.00146 \mathrm{~g}$ water $/ \mathrm{g}$ dry matter-min. VIR drying also produced the greatest head rice yield of $61.3 \%$. The experiment 2 presented that rice bran from VIR-dried parboiled paddy had the highest oil content of $0.256 \pm 0.041 \mathrm{~g} / \mathrm{g}$ dry matter and the most stable in term of minimum change in free fatty acid (FFA) content. The increase in FFA during storage for 14 days was $0.36 \%$. However, the increases in FFA of rice bran from IR- and HA-dried parboiled rice and normal rice were $0.38,1.36$, and $4.10 \%$, respectively.
\end{abstract}

\section{Introduction}

Parboiled rice is ranged in the top five exported rice products of Thailand. Three basic steps of parboiling include soaking, steaming, and drying. Hot air drying is the common drying technique used for parboiling. To improve drying in the parboiling process, VIR drying is considered as a promising technique. IR radiation provides more uniform heating than convective heating. It can reduce moisture gradient and stress development in rice kernels during drying [1]. However, to overcome short penetration depth of IR, mechanical vibration would be useful. Therefore, VIR drying was applied for parboiled paddy drying in this study.

After drying, the parboiled paddy must be subjected to rice milling process to produce parboiled rice. During the milling process, the valuable by-product, i.e. rice bran, is obtained and can be used as a raw material of rice bran oil production. IR radiation has been reported to be useful for rice bran stabilization as well. It can inhibit the reaction of FFA formation by inactivating the lipase enzymes in rice bran and then prolong the shelf life of rice bran oil $[2,3]$. However, researches mostly focus on direct IR treatment of rice bran. Report on effect of IR drying of paddy on its rice bran stability is very rare. Short cut the IR treatment of rice bran by applying IR radiation at the step of drying of paddy is of interest.

Therefore, the main aims of this study were to determine drying characteristics of parboiled paddy using VIR drying and to determine head rice yield of parboiled rice and stability of parboiled rice bran as affected by VIR drying of parboiled paddy. For comparison, IR drying and HA drying of parboiled paddy were conducted. Fresh paddy was also employed as a control as well.

\section{Materials and methods}

\subsection{Sample preparation}

Paddy of Khao Dawk Mali 105 was from Surin province, Thailand. It was vacuum packed with $5 \mathrm{~kg}$ per bag and kept in a refrigerator at $4-5^{\circ} \mathrm{C}$. The paddy was allowed to equilibrate to the ambient condition before using in all experiments. The initial moisture content of the paddy was $0.13 \pm 0.01 \mathrm{~g}$ water/g dry matter. This untreated paddy sample was refered to fresh paddy in this study.

\subsection{Preparation of moist parboiled paddy}

The paddy was cleaned and soaked in water at a temperature of $55^{\circ} \mathrm{C}$ for $260 \mathrm{~min}$ so that its moisture content was increased to $45 \mathrm{~g}$ water/g dry matter [4]. The soaked paddy was then steamed at $100^{\circ} \mathrm{C}$ for $20 \mathrm{~min}$ and tempered at an ambient condition for $10 \mathrm{~min}$ before drying.

\subsection{Architecture of the dryer used in this study}

The dryer used for IR, VIR, and HA drying is presented in Fig. 1. A double-walled stainless steel drying chamber was cylindrical with a diameter and length of 30 and 60 $\mathrm{cm}$. Two infrared heaters of $800 \mathrm{~W}$ each were installed inside the chamber at the top. The heaters generated a surface temperature of $750^{\circ} \mathrm{C}$ with the peak wavelength of $3.1 \mathrm{~mm}$. An aluminum cover was placed over the heaters as an infrared reflector. The perforated stainless

Corresponding author: jiraporn.jo@kmitl.ac.th 
steel drying tray $\left(0.20 \times 0.40 \times 0.05 \mathrm{~m}^{3}\right)$ was fitted in the chamber with the distance from the heaters at $20 \mathrm{~cm}$. The drying tray was mounted over a vibratory bed arranged to be vibrated vertically by a variable speed motor attached to an eccentric joint. Fin heaters of $4 \mathrm{~kW}$ and a blower of 0.5 HP were used for producing hot air. The hot air temperature was measured by thermocouples (type K, Lega model AK-01, Lega Coperation Co., Ltd., Bangkok, Thailand) and controlled by PID (Proportional-Integral-Derivative Controller) with an accuracy of $\pm 1^{\circ} \mathrm{C}$.

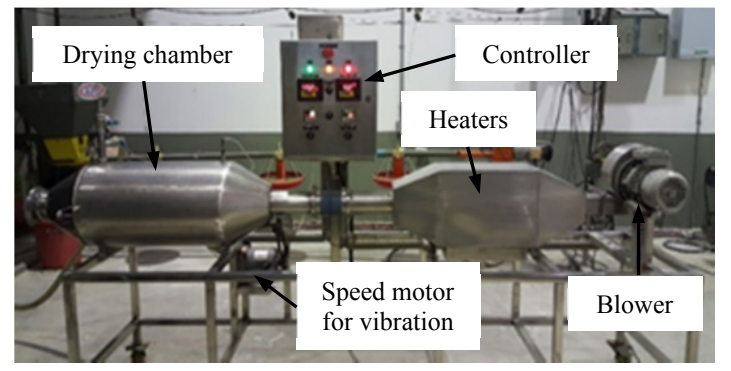

Fig. 1 A dryer used for IR, VIR, and HA drying.

\subsection{Experimental procedure}

The moist parboiled paddy (200 g) was dried by three drying techniques including IR, VIR, and HA drying. The infrared intensity used in this study was $750 \mathrm{~W} / \mathrm{m}^{2}$ for IR and VIR drying. To supply vibrational mechanism to the drying tray for VIR drying, the vibrational system was run at $500 \mathrm{rpm}$. HA drying was conducted at $100^{\circ} \mathrm{C}$. Air velocity was set at $1 \mathrm{~m} / \mathrm{s}$. The parboiled paddy was dried to the final moisture content of $0.13 \mathrm{~g}$ water $/ \mathrm{g}$ dry matter. During the drying process, the paddy was weighed at the predetermined intervals for moisture content determination. Drying characteristics were determined in terms of moisture ratio (MR) and DR as shown in Section 2.5. The dried parboiled paddy was milled and determined for its HRY as presented in Section 2.6. Rice brans obtained after milling these samples were stored and determined for its stability in terms of FFA (see Section 2.7).

\subsection{Drying characteristic determination}

Moisture content was determined in a hot air oven at $105^{\circ} \mathrm{C}$ for $24 \mathrm{~h}$ [5]. The equation for calculation of the moisture content in dry basis is as follows:

$$
M=\frac{W_{w}-W_{d}}{W_{d}}
$$

where $M, W_{w}$, and $W_{d}$ are moisture content (g water/g dry matter), wet weight of the material $(\mathrm{g})$, and dry weight of the material $(\mathrm{g})$, respectively.

MR and DR were calculated as below:

$$
\begin{gathered}
M R=\frac{M_{t}-M_{e}}{M_{i}-M_{e}} \\
D R=\frac{M_{t+d t}-M_{t}}{d t}
\end{gathered}
$$

where $M_{i}, M_{t}, M_{e}$, and $\mathrm{M}_{t+\mathrm{d} t}$ are moisture content (g water/g dry matter) at initial, specific time, equilibrium, and $t+\mathrm{d} t$, respectively; and $t$ is drying time (min). $M_{e}$ can be assumed to be zero when drying at high temperature and for radiation drying [6].

\subsection{Milling process and head rice yield determination}

The dried parboiled paddy of $200 \mathrm{~g}$ were dehusked using the testing husker (THU35B, Satake Corporation, Hiroshima, Japan). The resulted brown rice was polished for $3 \mathrm{~min}$ using the test mill (TM05, Satake Corporation, Hiroshima, Japan) to obtain milled rice and rice bran. The rice bran was used for the study in Section 2.7. Head rice and broken rice were separated using the rice length grader (TRG, Satake Corporation, Hiroshima, Japan). Head rice was defined as the rice kernel having a length longer than $6 / 8$ of the whole kernel length [7]. HRY was calculated by dividing the mass of head rice over the mass of paddy before milling.

\subsection{Storage of rice bran and determination of its stability}

Rice bran, the by-product obtained after milling, was packed in a $180 \mathrm{ml}$ polypropylene container and stored at the temperature of $25^{\circ} \mathrm{C}$ and the relative humidity of $50 \%$ approximately. The total storage time was 14 days. The stored rice bran was randomly sampled every two days for oil content and FFA evaluation. Oil contents of the rice bran samples were determined using the solvent extraction, AACC method 30-10 [8]. The extraction solvent was $n$-hexane. The values of oil content were expressed as g oil/g dry matter and reported as grand means. FFA content was determined by AOCS official method Ca 5a-40 [9]. The resulted rice bran oil after $n$ hexane extraction was dissolved in a mixture of ethanol and diethyl ether. The solution was titrated with a $\mathrm{KOH} / \mathrm{ethanol}$ solution. The values of FFA content were calculated as oleic acid equivalent.

\subsection{Statistical analysis}

The experiments were triplicated. Error bars in the plots present standard deviation. One-way ANOVA was used for statistical hypothesis testing. Duncan's multiple range test was used to determine the significance of differences between treatments at $95 \%$ confident interval.

\section{Results and discussion}

\subsection{Drying characteristics of parboiled paddy}

Drying characteristics of parboiled paddy undergoing different drying methods including IR, VIR, and HA drying are presented in terms of drying curves and DR curves as shown in Figs. 2 and 3. In Fig. 2, the drying curve of VIR drying exhibits the most rapid decrease in MR over drying time. To obtain the final moisture content of $0.13 \mathrm{~g}$ water $/ \mathrm{g}$ dry matter, VIR drying required the shortest drying time of $50 \mathrm{~min}$, followed by $60 \mathrm{~min}$ and $80 \mathrm{~min}$ for IR and HA drying, respectively. DR curves (Fig. 3) also presents that VIR drying resulted in the greatest maximum DR of $0.0146 \mathrm{~g}$ water $/ \mathrm{g}$ dry matter-min while the maximum DR obtained by IR and HA drying were 0.0109 and $0.0078 \mathrm{~g}$ water/g dry matter $\cdot \min$. These curves also shows that there were two 
DR periods, i.e. heating up and falling rate periods for IR, VIR, and HA drying of parboiled paddy.

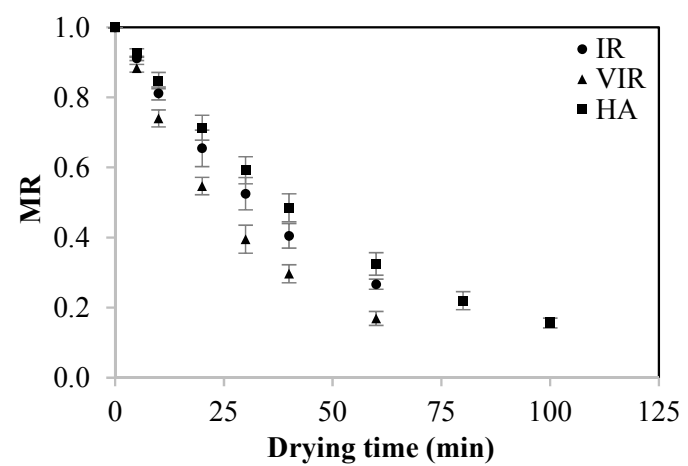

Fig. 2 Drying curves of IR, VIR, and HA drying of parboiled paddy.

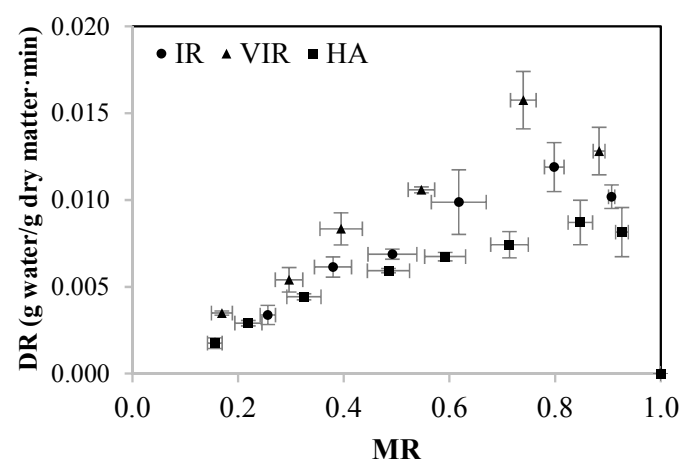

Fig. 3 DR curves of IR, VIR, and HA drying of parboiled paddy.

\subsection{Head rice yield of milled parboiled rice}

Head rice yield is the important parameter defining the quality of parboiled rice. During parboiling, rice starch is gelatinized, hence milling yield can be increased [4]. Fig. 4 shows the results of HRY of three parboiled milled rice and one untreated milled rice. Statistical difference of HRY among these sample was observed $(p<0.05)$. Athough all of the parboiled mill rice had higher HRY than the fresh rice, non-significant difference was obtained between the HA-dried rice and fresh rice. It should be noted that VIR drying of parboiled paddy resulted in the greatest HRY of the milled sample of about $65 \%$. The second highest HRY was obtained by IR drying of parboiled paddy as well. These results confirmed the benefit of IR radiation which can reduce moisture gradient and stress formation in rice kernels during drying and lead to higher HRY $[1,4]$.

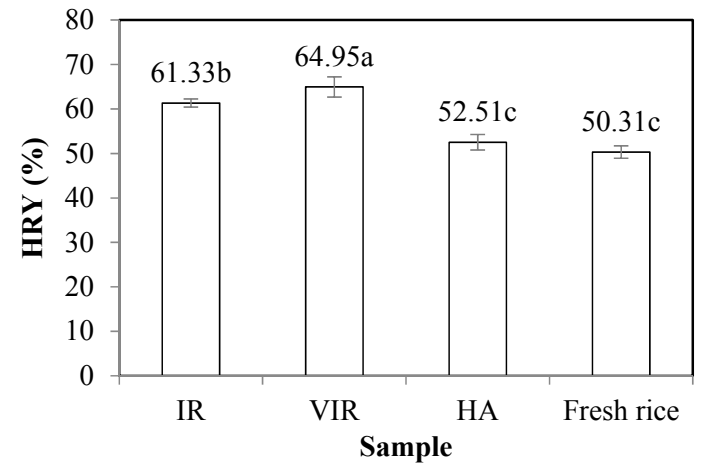

Fig. 4 HRY of milled rice from parboiled paddy undergoing IR, VIR, and HA drying and fresh paddy.

\subsection{Oil content and stability of rice bran}

Stabilization of rice bran (also known as enzyme inactivation process) is the process widely used to extend the shelf life of rice bran. Rancidity caused by presence of lipases is the key parameter indicating the shelf life of rice bran as it contributes to the development of offflavor and taste. During polishing, bran layers of rice are removed and individual cells are disrupted. Endogenous lipase enzymes hence cause the hydrolysis neutral bran oil to FFA and glycerol, which lead to the development of hydrolytic rancidity $[10,11]$.

In this study, rice bran samples obtained from polishing the parboiled brown rice were stored, oil extracted and determined for its stability. It is clear from Fig. 5 that oil content of the rice bran from VIR dried parboiled paddy was the highest. However, the values of oil content from IR, VIR, and HA drying treatments were not significantly different $(p \geq 0.05)$. Fig 6 presents the changes in FFA content of rice bran during storage for 14 days. At day 0, FFA content of each rice bran sample was about $0.7 \% \mathrm{db}$. FFA content of the rice bran from untreated paddy increased dramatically for the whole period of storage and reached about $5 \% \mathrm{db}$ at day 14. However, FFA contents of the rice bran from parboiled paddy were relatively stable during storage. HA drying of parboiled paddy led to slowly increase in FFA content of the rice bran and was about $1.7 \% \mathrm{db}$ at day 14. This Fig obviously presents that FFA contents of the rice bran from IR and VIR dried parboiled rice increased slightly and were about $0.9 \% \mathrm{db}$ at the last day of storage. Both IR and VIR drying gave the similar result of the best drying techniques applied to parboiled paddy for rice bran stabilization. In addition, these results confirm that we can short cut the IR treatment of rice bran by applying IR radiation at the step of drying of paddy. 


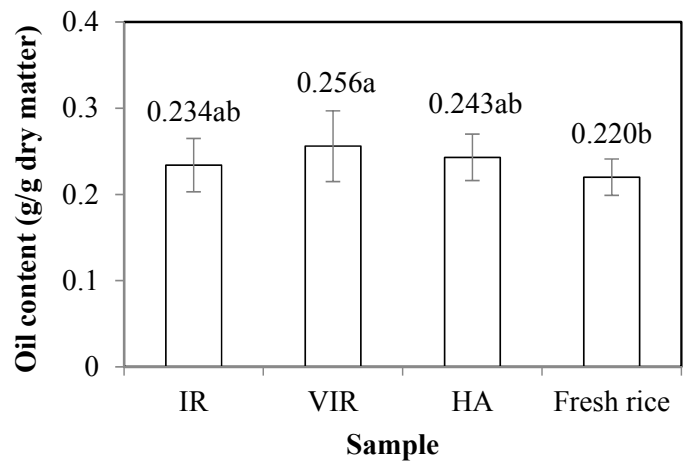

Fig. 5 Oil contents of rice bran from parboiled paddy undergoing IR, VIR, and HA drying and fresh paddy.

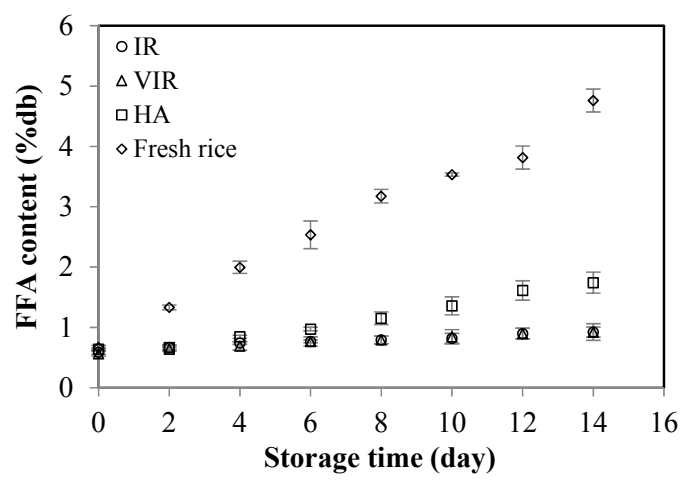

Fig. 6 Changes in FFA content of rice bran from parboiled paddy undergoing IR, VIR, and HA drying and fresh paddy during storage.

\section{Conclusions}

VIR drying was the most suitable drying technique providing the best drying characteristics of parboiled paddy drying and the best quality of parboiled rice as compared to IR drying and HA drying.

However, rice bran from the VIR, IR, and HA dried parboiled paddy was not significantly different in oil content. Both IR and VIR drying of parboiled paddy gave the similar result of good rice bran oil stability with their FFA consideration.

\section{References}

1. R. Khir, Z. Pan, A. Salim, B.R. Hartsough, S. Mohamed, LWT-Food Science and Technology 44, 1126-1132 (2011)

2. N. Yilmaz, Food Chemistry 190, 179-185 (2016)

3. T. Wang, R. Khir, Z. Pan, Q. Yuan, LWT-Food Science and Technology 78, 281-288 (2017)

4. P. Bootkote, S. Soponronnarit, S. Prachayawarakorn, Food Bioprocess Technol 9, 1574-1586 (2016)

5. AOAC, Official methods of analysis (Association of Official Agricultural Chemists, Washington, DC., 1995)
6. C. Contreras, M.E. Martin-Esparza, A. Chiralt, N. Martinez-Navarrete, Journal of Food Engineering 88, 55-64 (2008)

7. FAO, http://www.fao.org/docrep/x5048e/x5048E1o. gif

8. AACC, Approved methods of American Association of Cereal Chemists (The Am. Assoc. Cereal Chem. Inc., St. Paul, MN., 2000)

9. AOCS, Official methods and recommended practices of the American Oil Chemists Society (American Oil Chemists Society, Champaign, 2004)

10. K. Gul, B. Yousuf, A.K. Singh, P. Singh, A.A. Wani, Bioactive Carbohydrates and Dietary Fibre 6, 24-30 (2015)

11. S.M. Kim, H.J. Chung, S.T. Lim, Journal of Cereal Science 60, 243-248 (2014) 